\title{
The Rise of Information and Communication Technology Era in the Israeli Educational System
}

\author{
Ben-Zion Barta ${ }^{1}$, Liora Shapiro ${ }^{2}$, Daniel Millin $^{3}$, and Ephraim Engel ${ }^{4}$ \\ ${ }^{1}$ Retired Chief Inspector on Computers in Education, Ministry of Education, Israel \\ ${ }^{2}$ Teacher and Educator, Yisgav Elementary School, Tel-Aviv, Israel \\ ${ }^{3}$ Passed away, Head of the Counseling Team on ICT in Teaching / Learning \\ ${ }^{4}$ Passed away, Head of the Counseling Team on ICT in High Schools \\ benzion@barcode.co.il
}

\begin{abstract}
This chapter is an overview of the development of ICT in Israeli Education, from the first pioneers in the second half of sixties to first half of the nineties, when I (first named author of this chapter) gradually passed on my responsibilities, near to my retirement. It covers policy matters, as revealed in the first published policy papers, some of the main actions and projects executed according to these policies - integrating ICT in the learning process; teaching ICT subjects; integrating use of ICT means in humanities, sciences and professional education; ICT in educational management; principals', teachers' and staff training, support and updating and some related organizational details. It ends with a glimpse to recent problems and policy decisions.
\end{abstract}

Keywords: Computers in Education, Israel, schools.

\section{Introduction}

I, the first author-named of this chapter, have been deeply involved with the rise of educational computing activities in Israel, as part of my responsibility as Chief Inspector on Computer in Education at the Ministry of Education of Israel, from the mid-seventies to the mid-nineties. Under my eyes, within a decade or two, computers penetrated the educational system:

- From no computers, then the first PDP8s, the first Apples Commodore, Radio Shack and IBM compatible PCs, to thousands of networked microcomputers connected to the Internet;

- Starting from a few people from academia or who industry volunteering to give a general introductory lecture about computers, ending with Computer Sciences and IT professions taught as regular subject matter similar to other sciences;

- From simple drill and practice in arithmetic to sophisticated educational applications getting into the teaching / learning of many subject matters.

- I have seen the kindergarten teachers and primary and high school teachers learning how to use computers, how to manage their computer corner. 
- I have seen the Chief Inspectors, the staff and the high school teachers of sciences, humanities, languages, professions, getting interest in the world of computers and finally introducing them into their regular teaching.

This chapter is an overview of the development of ICT in Israeli Education, from the first pioneers in the second half of sixties to first half of the nineties, when I gradually passed on my responsibilities, near to my retirement.

The chapter is not a precise, scholarly historical review; rather, it is based in large on personal memoirs, on some papers I published while being with the Ministry [2][3], some documents - old ones and newer ones. While I did my best to mention the main facts and events - it is obvious that many remain uncovered in this chapter and I can only apologize about this fact.

My thanks to Liora Shapiro, an appreciated ICT manager, now dedicated to ICT integrated teaching, who helped collecting the sources and preparing the text of this chapter.

I cannot write this chapter without mentioning the memory of two persons that shared the daily burden, both of whom passed away a few years ago, namely Ephraim Engel who was head of the counselling team on ICT in High Schools, and Dr. Daniel Millin, who was head of the counselling team on ICT in Teaching / Learning. Had they been alive, they would have been co-authors of this chapter. In memoria, I decided to add their names besides mine.

Tens of dedicated colleagues worked with us to accomplish the task; many are taking care of the field after us. I could not mention all these devoted colleagues.

\section{Local, Institutional and National Policies}

\subsection{School, Municipal, Academic and Industrial Initiatives for Integrating ICT}

At a time when computers were scarce and with very limited capability compared with today, promotion of computer related activities in education started by initiatives of schools, school networks, municipalities, in cooperation with academia and industry. These initiatives resulted in the first acquaintance of pupils with computer concepts and the first computer aided learning activities at the end of the sixties and start of the seventies of the last century [6].

Several schools - some supported by academia or by industry, some by their own volition - have been involved with such initiatives. Some examples: one technological high school in Jerusalem, having a computing department, used computers to teach, in addition to Computer Sciences, applications for typesetting and numerical control and developed a software package to manage students' scores and attendance; another school, in Kiryat Shmona near the Lebanese border, was among the first to get microcomputers to be used for Computer Sciences teaching and some administrative services; a third example is a school in Kiryat Ata, near Haifa that got six micros and used them for teaching computer concepts to young pupils at fifth to ninth grade. There have been several additional schools taking initiatives to teach Computer Sciences - all these initiatives received recognition by the Ministry of Education, in the form of approval to include the subject in the matriculation examinations. A few 
universities offered extracurricular introduction to computing to interested youngsters, and some provided regular teaching to schools.

A proposal to train computer programming professionals within the technological education schools was approved by the Ministry of Education in 1968, and several high schools offered this track - Automatic Data Processing - dedicating to it some 20 weekly hours (out of a total of 45) for 3 years.

At a larger scale, aiming at the national schooling system, the Center for Educational Technology, an institution founded by the Rothschild Foundation in 1970 , set as its goal to introduce technological innovation to the Israeli educational system. Among other projects, two were directly related to Information Technology, namely: Development of curricula for teaching introductory computer science at the high school level; integrating the use of computers in the teaching process of basic subjects, in order to promote pupil's achievements, mainly for underachievers.

All these beginnings, supported but not initiated by the Ministry of Education, caused the Ministry to consider the foreseeable impacts of Information Technology on the educational system and to define its policy.

\subsection{National Policies}

In 1978 the Ministry of Education dedicated the first small budget to Computers in Education. Coordination of the institutional initiatives started about the same time.

In 1979 The Committee on Computers in Education headed by the Chair of the Pedagogic Secretariat of the Ministry (the highest ranking officer dealing with educational and pedagogic matters) was appointed - see \# 2.2.1.

A substantial increase of funding was approved for the 1983/84 budget, following several seminars and discussions held in 1982, aiming to decide upon the policy and the main goals for using the budget.

One of the first documents dealing with the involvement of the Ministry of Education in educational computing matters was a proposal submitted to the Director General of the Ministry in 1980, dealing with the whole spectrum of issues as seen at that time. The main goals of introducing IT in the educational system, as understood at that time:

- All pupils will have a first acquaintance with computers within their compulsory education, including their operations and limitations, and will use computers and computerized systems in their daily learning activities. Understanding ways and approaches to use computers shall be emphasized, rather than programming.

- Any interested pupils will have the possibility to study Computer Sciences and professional computer applications.

- Teachers and educational employees will use computers as support for their daily activities.

- It had been envisaged that using computers within the teaching and educational activities shall start at early ages from kindergarten and up, and be effective to all levels of pupils - from special education to the most gifted ones. Computer literacy, as formal learning in schools or informal, at extracurricular activity centres, should start at fourth grade and up, while using computers for problem solving, deeper study of Computer Sciences and professional applications shall start at seventh grade and up. 
Several documents written in the early eighties defined several prioritized fields of activities:

- Compulsory learning of computer concepts and educational applications of computers at all Schools and Colleges of Education to the entire student population and in-service training and updating of teachers. This learning should cover methodologies of integrating computer-based activities in teaching/learning, courseware evaluation, courseware authoring, selection and adaptation of activities to the needs of the pupils.

- Further development of Drill and Practice of basic skills, development and implementation of a variety of approaches to integrate computers into the learning process. The re-organization of the classroom has to be considered as well as individual learning and learning in small groups.

- Development and state-wide implementation of curricula for Computer Literacy, Computer Sciences and computer related vocational education and related teacher training.

There was at that time some euphoria concerning the capabilities and the expectations from computer usage in education. However, some 'cooling down' ideas have also been exposed:

- The teacher, the educator, the human being, will always be the one to take decisions, to control and guide the technological means and will be the dominant and main factor in the educational system - the technology being a tool, maybe important, to the service of men.

- Technological means have the capability to improve and modify the learning process, may help solve some difficulties and problems, but they have limited capabilities to solve the hard, real problems encountered in education. They will never be better than the men behind, that designed and developed them.

\subsubsection{The Committee on Computers in Education}

This committee was appointed in 1979. Its mandate was to determine policy and activities at state level. The committee members were the heads of the main educational divisions of the Ministry (e.g., primary, secondary education), representatives of administrative divisions, academics involved in computers in education, school principals and teachers.

In 1983, the committee reported on the main activities as covering [1]:

- Teachers' training and updating - pre-service and in-service;

- Curricula development - computer literacy, computer sciences, data processing professionals, professional and scientific applications;

- Computer aided learning - drill and practice, individualized learning, educational games;

- Integration of computer activities in teaching/learning, audio-visuals, data banks, use of LOGO language;

- Equipment - advice, financing;

- Support centres for schools and teachers;

- Central supervisory and advising teams. 
Following several years of activity, periodical discussions about the needs and achievements, re-assessment of earlier decisions and consideration of the criticism and the variety of opinions, a two day discussion with interested and involved parties lead to a document published in November 1986, defining the policy in the field of computers in education [9]. Several tens of people from academia, industry and the educational system took part in these discussions. Suggestions and proposals from the general public were solicited and considered. When reading the following lines, one should remember the time they have been written and appreciate the vision of the participants and their deep understanding of anticipated developments. Most of the decisions and recommendations as concluded then are still accepted today some, perhaps, are still waiting for implementation.

\section{The following is a short summary of the approaches and decisions as published in the document:}

The world of computers is dynamic and rapidly changing, while the educational system has difficulty to adapt to fast changes; however decisions have to be taken even if some may be outdated and unfit for future developments.

The Information and Communication Technologies ( $\mathrm{ICT}^{1}$ ) have great potential for teaching and learning and their capabilities are immense, but they carry many dangers too and have limitations.

The revolution of communications means will lead to another school, different from that of today. The ways of teaching and learning will change with penetration of ICT in each classroom and in each home. The development and the improvement of ICT will deeply influence the educational system and its operation.

ICT is not the goal; it is a means to efficiently solve some problems of the educational system but will not solve some of its hardest difficulties. In order to realize the potential of ICT many practical problems have to be solved, technical and pedagogical and while doing so, no doubt many mistakes will be made.

The big challenge is to learn and to teach using ICT wisely and soundly, for proper functioning in the ICT world.

The main areas that ICT may support:

- Planning, operating and controlling learning systems at all levels: individuals, classes, schools, regional and national (organization and management of learning);

- Collection, processing and distribution of information;

- Improvement of teaching / learning process;

- Improvement of cognitive processes: planning, systematic thinking, problem solving, abstraction.

The main fields of activity:

- Training of man-power to be intelligent users of the means of ICT:

○ All employees of the educational system, at all levels - adequate to each one's tasks;

- All teachers and students at Schools and Colleges of education;

○ Teachers of computing at all levels and all nuances;

\footnotetext{
${ }^{1}$ This is the first time that the term ICT was used in relation to Computers in Education.
} 
- Teachers of sciences, humanities, technologies, etc. - each one according to ICT uses in the relevant field;

- Specialists in ICT applications in education - students toward MA and $\mathrm{PhD}$ degrees;

- Infrastructure:

○ Logistics:

- Hardware, software, courseware: specifications, evaluation, licensing, purchase, supply, maintenance;

- Limitations as to the variety of products and the rate of their updating;

- Guidelines concerning funding for purchase of materials;

- Communications:

- Set up of two logically separated regional / national networks

- For distribution of courseware, educational information banks, learning and personal communications;

- $\quad$ For educational management of the educational system;

- Set up of two physically separated school networks:

- $\quad$ For ICT based teaching /learning and management of learning at individual and school level.

- $\quad$ For educational management, and downloading information from the regional / national network;

- Defining models for integration of ICT in the operation of schools lab, class, library, applications library, connections to homes;

- A national network to deal with coordination of research, development and evaluation of courseware by collaboration of all institutions active in the field;

o Planning of man-power requirements in short term and long term;

- Planning and encouraging basic research; Evaluation of the benefits of integrating ICT in education and of its costs;

- Defining procedures for software development, use of applications, protection of software, documentation and training; defining procedures for development of curricula; systematic check of curricula in mathematics, sciences and technologies to decide upon the need for updating them; ongoing use of computers for problem solving;

- Creating means for distribution of information about activities in Israel and abroad in the fields of ICT in education; setting up a database about courseware and curricula in the ICT field in Israel and abroad;

o Defining the professional-administrative structure in the Ministry for implementing and supervising operations related to ICT; guidelines for planning of buildings (new and old ones) for ICT infrastructure;

- ICT in Educational Management

o Defining a master-plan to deal with:

- Analysis of the data system and of the administrative structure;

- Requirements regarding equipment for data processing and communications;

- Evaluation of costs;

- Long range plans of implementation; 
- The first step: the school secretariat - using ICT for collection of data and decision making; usage of word processors and communications;

○ Defining approaches for ICT in regional / national management;

$\circ$ Building up banks of problems, questions, their selection and evaluation having in view using them for generation of examinations and their assessments - perhaps integrated with the management of the individual learning of pupils;

- Use of ICT in teaching and learning:

- ICT as subject of learning:

- Computer Literacy:

- $\quad$ Skills shall be gained by using computer applications within the teaching of subject matters in primary schools and junior high schools - no formal teaching of ICT subjects;

- $\quad$ Computer Literacy as a subject of study at junior high schools;

- Computer Sciences and Data Processing:

- Selective subject of learning at basic or advanced level in general high-schools;

- $\quad$ Basic Computer Sciences - compulsory for all pupils of technological and agricultural high-schools;

- $\quad$ Learning of specific professional applications - compulsory for pupils of almost all tracks of technological and agricultural high-schools;

- $\quad$ Professional training to pupils of the Data Processing track of technological high-schools;

- Use of ICT means and application:

- Use of ICT means shall be intensified, as an integral part of the learning:

- $\quad$ Advanced use of word processors - free writing, language learning, assignments;

- Usage of databases; processing and display of data;

- Access to real information banks, as part of learning any adequate subject matter and for pupils' individual assignments; creation of educational databanks as subsets of real ones; databanks specially created for pupils' use;

- Use of software packages within learning of technologies, sciences and any other subject matter;

- $\quad$ Communications - (e-mail, group and peer networks) within formal and extracurricular activities;

- Integrating of ICT in the learning process shall be done in various ways - active and individual teaching, in laboratories, learning centres, learning corners in the class room, part of frontal teaching but only if there is a clear advantage of ICT over conventional learning;

- Drill and Practice shall be used to improve achievements in basic skills; 
- Pupils' Assessment and Educational Feedback: this is an important field of ICT application in educational management that still needs research and development:

○ Banks of items for assessment of achievements and for diagnostic examinations;

o Ways of integrating the assessments in the teaching / learning process;

○ Ways of providing feedback at institutional and higher levels.

- Populations: the variety of ICT related activities has impact on the different populations involved in the school system. Priorities have to be defined among the following (the list is not by priority):

o Teachers and staff dealing with any aspect of ICT;

- General, technological and agricultural high school pupils;

- Primary and junior high school pupils;

- Special education pupils -including diagnostics and parents training;

- Kindergarten pupils;

○ Extra-curricular and informal education for youngsters and adults;

o Any others.

\subsubsection{Other Reports and Committees}

The report of activities (1983) and policy document (1986) of the committee on computers in education (\#2.1.1) were the first published guidelines at the level of the national educational system. Different institutions and committees have published other policy recommendations. While there have not been many new ideas, some ideas faded out; others received varying emphasis, influenced by the changes of approaches and technological means.

A report published in 1985 by the Ministry of Science and Development and of the Ministry of Communications [10] recommended initiating a national program for development of computer based teaching systems, having in view two goals: the commercial potential of export and the advancement of the national education system. A committee appointed by the Ministry of Education recommended supporting the initiative, mainly having in view that it would aim to have computers as an integral part of the educational system and the potential for far reaching changes of the whole system. Even if the program did not materialize, the related discussions in the Ministry have contributed to build up basic ideas of a national policy.

An internal document of the Primary Education Department of the Ministry, published toward the mid-eighties, was dedicated to integration of ICT into the teaching curricula. It defined as its goals:

- Improvement of the teaching / learning process:

o Of learning achievements, of cognitive capabilities,

○ Of daily use of ICT applications;

- Strengthening of communications and cooperation among pupils, between pupils and teachers, between school and community;

- Improvement of school and class management. 
These short and simple looking goals have probably been a main catalyst of the development of the vast variety of activities mentioned in \#3 and of the todays' approach of 'each kid with the tablet in the bag'.

Another report, published in 1991, dealt with various subjects, some already covered by previous decisions, others rather new:

- Implementing a nationwide plan to integrate ICT in teaching / learning activities;

- Ensuring the proficiency of teachers and principals regarding selection and application of ICT based pedagogic means;

- Modification and adaptation of existing curricula to have them ICT centred;

The 'Harari Committee', headed by Professor Haim Harari of the Weitzman Institute of Science, was appointed by the Ministry of Education to assess the scientific and technological education in Israel and to recommend a plan of activities for the forthcoming years. In 1992 it published its report entitled 'Tomorrow 98' [14], fully covering aspects of education in mathematics, sciences and technologies, as basic knowledge and as advanced learning within the school system. The report dedicates a separate chapter to 'Computers as support for teaching', based and fully accepting another report, 'Proposal for a policy on Integrating Computers in Teaching and Learning in the Educational System' published in January 1992. Some of the rather new recommendations were:

- Computers in Kindergartens: improvement of learning and usage of computer environment. The activities shall cover: development of courseware and of curricula integrating computer uses. Priority shall be given to disadvantaged populations and to peripheries.

- Computers in Elementary Education: integration of computers in the learning of most subject matters with the whole range of activities enabled by ICT; equipment shall be available in the class room, the teacher's desk, laboratories, central computer room, library; a computer coordinator officer shall be appointed to take care of the whole system; pre-service and in-service training; support centres.

- Computers in Junior High Schools: Computer Literacy shall be compulsory; learning of all subject matters shall be computer embedded.

- Computers in High Schools: learning of mathematics, sciences and technology shall be computer embedded; ICT shall be used for problem solving, simulations, investigations, gathering, processing, analysis and display of data.

- Computers at Schools and Colleges of Education: computer literacy and basics of computer-based learning - compulsory subject for all students; integration of computers in teaching of all subject matters; in-service training and updating of all teachers of Schools and Colleges of Education.

- Computer communications: all aspects of ICT integration in teaching/learning shall be considered; adequate educational activities shall be developed and tried out in several pilot projects; setting up of a central information centre for the educational system shall be considered. 


\subsection{Organizational Details}

This section describes some of the ways selected for carrying out the policy for ICT in education.

\subsubsection{The Professional Committee on Teaching of Computer Sciences}

The committee was responsible for creating and updating curricula, examinations, curricula for teachers training, licensing of teachers, and any other matter related to teaching of Computer Sciences at any level in the school system. Its members were computer scientists from academic institutions, people from the IT industry, teachers and supervisors of Computer Science teaching.

\subsubsection{Computer Equipment for Schools}

Dealing with this matter started with the appointment of 'The Committee on Computer Equipment for Schools'. Its members were administrative people and some professionals and pedagogues. Its roles: improving the terms of purchase and maintenance of equipment, promoting standardization and local development of computing equipment for schools. These activities lead to two main outcomes:

- Publishing requirements for systems to be supplied to schools and actually approving suppliers; the process of suppliers' approval was repeated every year / second year.

- Setting up of a centre for licensing courseware for use in schools.

\subsubsection{Counselling and Supervising Staff}

Two teams of supervisors/counsellors were set up to promote and support the ICT related activities. They had two tasks, sometimes contradictory, but mostly feasible, together: on one hand to ensure that activities in schools are carried out as expected, according to the regulations and guidelines; on the other hand, to provide guidance and counselling to teachers, principals and school staff regarding all issues related to ICT. An important role was to explain to the school principals about ICT, the related difficulties and advantages, to convince them to step into the ICT era and to introduce and support the new activities in their schools - the involvement and support of school principals was an important factor for the success.

One of the two teams dealt with the high-schools and was mainly involved with the teaching of ICT related subject matters at all levels, while the other team dealt mainly with elementary schools, being involved with the different aspects of integration of computers in the teaching / learning process. This second team was directly involved in setting up the regional support and advice centres, guiding their work, some of the supervisors becoming even part of the team of the centres.

\subsubsection{Regional Support and Advice Centers for Computer Applications in Education}

These centres have been created to help solve difficulties in usage of computers in schools and to promote usage of computer activities - the existing ones and those 
being developed. The difficulties seemed to be the outcome of the fact that many schools preferred not to use the packages distributed by organizations providing the required support. Some of these schools found that the technical problems, sometimes inadequately prepared software and pedagogical problems, caused in some cases more frustration that enjoyment.

Each centre was to provide support to schools in its region - to have enough qualified manpower to ensure personal contact with interested teachers. In the centre (available also out of teaching hours) teachers could find samples of various equipment, including networks, as used in the schools, the variety of courseware, a library of related books, full information about courses offered to teachers, and any other means considered necessary. They had to be open to interested teachers coming to the centre but had as well to go out to visit the schools and to help solving their problems on the spot. Some offered telephonic 'hot lines' to help solving operational problems that may occur in the schools.

As expected, the centre did promote the goodwill of inexperienced teachers to step into the computerized world and contributed to the progress of computer usage in the schools.

\subsubsection{Budgets}

The yearly budgets dedicated by the Ministry for Computers in Education were not intended to purchase equipment for schools. Purchase of equipment could be covered by this budget only as part of budgeting of a supported project. The main items covered by the budget have been:

- Development of courseware and methodology for integration of computers in the teaching / learning process;

- Teachers' training and updating;

- Supervision, guidance and on-going teachers' support;

- Development of curricula;

- General research and development;

- Educational management.

On the other hand, purchase of school equipment has been paid for from budgets of The Israeli National Lottery, local educational authorities and parents' organization. Among the criteria for allocating money for school equipment:

- Presence of a coordinator for the school computing activities and of trained teachers;

- The equipment already available - the planned usage of the equipment with the addition;

- Availability of an adequate room - size, light, ventilation, etc.;

- The distance to nearby facilities that could provide computing activities;

- At that time (mid-eighties) the concept had been that pupils get to a computer lab in groups; the recommended number of stations being not less than $25 \%$ of the class size; if the lab would be in use more than half of the available time, the number of station should be $50 \%$ of the class size or even equal to it. 
- In some special cases allocation for purchase of one or two stations has been considered.

- A school could decide to divide the computers, several stations in a class room, instead of installing all stations in a lab.

\section{Integration of Information Technology in the Learning Process}

Computer Aided Learning, as we used to call it in the mid-seventies had some local beginnings by school initiatives, some mentioned in \# 2.1. Larger scale projects, initiated by public institutions, some financially supported by the Ministry of Education started their activity at the same time (1975 - 1980) [8]:

The largest and longer lasting, the TOAM (Hebrew acronym for Drill and Practice), initiated by the Centre for Educational Technology, had as its first goal the adaptation of the arithmetic Drill and Practice developed by Suppes at Stanford University in the USA. It had to be adapted to the Israeli curricula and made available at affordable prices. A dedicated, alphanumeric multi-terminal system has been developed, capable of delivering the individualized courseware to 16 or more pupils at a time, keeping track of each pupil's achievement and adapting to it the individual teaching sequence, keeping pupils' records and generating a variety of educational reports for teachers' and principals' use.

Aiming to provide the system to tens and hundreds of schools, a logistic and administrative infrastructure has been developed to supply hardware, software, courseware and maintaining them. Another aspect of this large scale project was teachers' training about the educational uses of the system, the integration of the activity in the class room teaching, the analysis and interpretation of individual and the class reports. Ongoing educational guidance and support on the same issues, has been provided.

Further developments: courseware for a variety of subject matters (e.g. Geometry, Hebrew and English language skills, reading, basic electricity); more advanced graphic terminal; improved computing power.

The Institute for Teaching Aids, in cooperation with the Junior Technical College of the Technion - Israel Institute of Technology - developed the MACAL (Multimedia Approach to Computer Aided Learning) system. The learning materials included textbooks, computer controlled learning interaction - branched based on individual achievements of each pupil and teacher's decisions - models and simulations, short educational television shots.

The first system based on alphanumeric multi terminal mini computers was later adapted to microcomputers.

Teachers and course authors got reports of progress and achievements; template based authoring aids allowed generation of courseware without any knowledge of programming.

Teachers' training and methodological seminars helped to develop adequate pedagogical approaches. 
The subject matters that have been covered aimed to high school students introductory computer sciences, algebra, elementary English, auto-mechanics.

Although well accepted and appreciated, the use of the system faded out as team members left to other commitments and as no preparation for spreading out to large scale use were done.

Another project worth mentioning is MASHOV (Hebrew word for Feedback) initiated by the Ben Gurion University in Beer-Sheba in cooperation with two primary schools and one high school.

The basic idea was to develop learning activities with strong cooperation between the classroom teachers and the team at the University. The computer was used to provide tutorial dialogs for individual learning, drill and practice and educational games. Subject matters covered arithmetic, algebra, reading and Judaism.

At the beginning, alphanumeric terminals, connected by phone lines to the university computer had been used. Later the courseware was transferred to microcomputers with graphic and colour capabilities.

As such the MASHOV project faded out - some of the staff remaining with the university and promoting educational computing activities, in cooperation with the local schools and new projects; others left for commercial activities in the field of educational computing.

A bit later, in Kiriat Shmona, a group of teachers started the SEMEL (Hebrew acronym for Computer Assistance for Teaching) project - based on microcomputers, mainly drill and practice of basic primary school subjects, but including other learning activities, such as games and simulations with graphics as available in that times. While a full set of activities was provided by the basic system, including collection of pupils' individual data and setting each one's learning path, teachers had the liberty to add their own materials and to modify the selection of materials presented to each pupil. Thus, teaching contents and learning control have been under a mix of system decisions and teachers' control. This liberty was attractive to many teachers, even if the time and effort needed to benefit of it, were an obstacle to fully enjoy it.

Availability of SEMEL on microcomputers - rather cheap and flexible as for system size - has been another attractive property of this approach. A central institution cared for logistics and maintenance and provided teacher training and ongoing support. The system was widely accepted within the schools, perhaps second in size in Israel.

One of the issues of disagreement among the different teams was the degree of freedom given to the individual teacher to manage each pupil's activity and to modify or add-on to the prebuilt teaching system.

On one hand, the prebuilt system is the result of the effort of a pedagogic team, specializing in courseware development, using feedback to improve their materials. Having this in sight, the individual teacher should just master the available system and learn to interpret the data collected about each pupil.

On the other hand, the teacher using the system and teaching his pupils, may know better what is needed for teaching the subject being dealt with, what are the needs of each one of the pupils and what would be the best way to support his/her learning. 
Obviously, life is a compromise in many cases: provide self-standing systems that can operate without teacher's intervention, but provide the possibility to intervene when the teacher decides to do it.

About the mid-eighties a Department for Computer Based Curricula was set up within the Division of Curricula Development of the Ministry of Education. The role of the department was defined as help in integrating adequate usage of computers within the media available for teaching / learning. It had to be done for new curricula being under development as well as for existing curricula that was available and stable. The goals were defined as improving the teaching in general, individualization of learning, and better adaptation of the teaching process to heterogeneous classes.

Teams of teachers active in schools, dedicating some of their time to courseware development were involved in a decentralized approach promising better use of local talents, having immediate effect on the school activities and providing immediate feedback. National and regional coordinators took care of the guidelines for the regional teams and of the wide scale distribution of the finished products.

Subjects covered have been: Hebrew (as mother tongue), English (as foreign language), Arithmetic, Algebra, Geometry, Judaism, Biology - to mention just a few.

A major project, daring to computerize the educational system of a whole township - the 'Mehish' project started in 1985 by the initiative and under the management of the staff at the School of Education at the Ben-Gurion University in Beer-Sheba. It was active in two townships, mostly in Arad. It intended to reach an overall understanding of the computerization process and a comprehensive policy for the township having as its goals: to create a 'computer culture' in the schools; to create a supporting environment to the schools; to initiate changes and renewing of teaching and learning, having the computerized environment as a catalyst and provider of changes.

The project ran between 1985 and 1989 when individual personal computers were scarce. It reached some conclusions that have to be taken in account by any large scale project being execute these days. Among the conclusions of the project:

- Changes of the teaching / learning approaches in the elementary schools by the computer culture is to be expected if:

○ Pupils have at least 3-4 hours of computer activities per week (1985-89);

- Computer based activities are integrated in most subject matters and most stages of learning;

- Computerized activities are adjusted to the specific needs and approaches of pupils, teachers, and class;

- Computerized activities are integrated in the normal classroom activities, by having several computers in the classroom

- Isolated interventions cannot achieve a computer culture - everybody has to master basic computer skills: pupils, teachers, staff and management.

- Significant outcomes of computerization can be achieved after a gradual process, lasting several years, conditional upon:

o Cooperation with the teachers and the school staff for planning and execution of activities;

- Cooperation with and support of parents and of local authorities;

o On-going counselling and training of teachers and staff; usage of computers in most of curricular and extracurricular activities. 
The kindergartens got their first 'computer corners' in the early eighties by an initiative of a team at the Oranim College of Education in Tivon, near Haifa. Its basic approach was to adapt LOGO style activities aiming to develop the children's capability to 'define problems', to plan solutions and test them, to be able to think about the outcomes of a sequence of actions. At the beginning, kindergartens came with groups of children to the site of development, to act under supervision, aiming mainly to study the behaviour and the acceptance by the children. Soon, it migrated to the kindergartens, each having a corner with a few microcomputers, assigned in turn to pupils. The materials were soon enriched by other sorts of educational activities, offered by the same team or by others, either from the public sector or by commercial firms.

The open minds, the enthusiasm and acceptance of the idea by the supervisors of the Ministry of Education and by the kindergarten teachers played an important role in the acceptance and success of the initiative, despite the initial doubts about its feasibility and about the capability of the teachers to overcome the technical difficulties. Large scale implementation started in 1988 and in 1991 computer based activities were included in the formal curricula of kindergartens.

In special education, the use of computers started with use of available courseware considered to be adequate to pupils with special needs. A team at the University of Tel-Aviv developed special courseware and methodologies dedicated to these pupils.

Further courseware development was carried out by teams at Universities and Colleges, by public and commercial organizations, too many to mention. These did care also for full curricula, but rather focused on specific subjects, dedicating to each subject the most adequate approach. They initiated development of courseware in a myriad of approaches - tutorials, exercises, simulations, 'computerized' laboratory, drill and practice, games, applications, etc. - good for execution on different computers, as stand-alone applications for use by students in their learning or by teachers in their teaching in the class room. These applications did not require dedicated computers and could co-exist on the same machine, ready for invocation by any (authorized) user. The selection of the actual means - could be managed by the computer, or the teacher, or the pupils or a mix of these options.

Once schools were ready to spend money on courseware, private, commercial firms got in the arena - some of them, set up by initiators of publicly funded projects that switched their interest to private initiatives. They dealt with production of original applications and with translation and adaptation of courseware developed in other parts of the world.

The use of commercially available word processors and spreadsheets, in some cases special educational products, started to be common in teaching humanities and sciences, in many cases by assignments specially designed having the use of these tools in sight.

Computer based activities were not restricted to the formal schooling system. Extra-curricular activities were available at various environments at youth clubs, computer clubs and even in schools out of the regular teaching frame. 
The abundance of materials available and offered to the schools by many different sources soon raised the question of what materials are adequate for use. Issues of accuracy of contents, pedagogic and ethical approach, correct language, technical aspects, support of users, had to be considered when deciding about courseware offered to a school.

The need of objective (as possible!) evaluation of courseware and of providing adequate information to the interested parties brought about the decision to set up a centre for evaluation and licensing of computer baser learning materials. The Ministry of Education initiated setting up such a centre that became operative in the late eighties.

Surveys conducted in 1989/90 had as their main results, the following facts:

- There was about 1 computer per 15 pupils, most of them in computer labs, some in the classrooms;

- The variety of uses covered: teaching Mathematics, Hebrew, English, Computer Literacy, LOGO, Basic, Sciences, Geography; usage of word processors and databases; extracurricular activities.

- Daily use of computers was reported by about half of the schools. The general feeling was that the technology could be used more effectively and more sophisticatedly:

- Many teachers felt they lack knowledge and sufficient guidelines for effective use of computers;

- Printers and peripherals were insufficient;

- More courseware was needed;

- More time should be dedicated to computer activities in the school's schedule.

The operational conclusions of the surveys: more teachers' training, better planning of educational computing activities, more equipment, was needed. These conclusions may apply nowadays as well.

In the early nineties, as the Internet was growing, its potential for support of educational innovation was considered. Proposals were popping up to set up active interest groups, to improve direct and interactive contacts between colleagues and teams and inter-teams cooperation; it was considered as provider of links to global information resource, as a support of educational innovation.

First pilots were set up to provide personal mail services, bulletin boards, discussion groups, information banks, news bulletins.

All these provided a good entry point to the more developed general networking systems that became available over the years.

By the mid-nineties, as the Internet grew and became more accessible, the use of the Internet search engines became a companion of the existing learning activities.

\section{Teaching of Computer Sciences - Academic and Professional}

Computing appreciation courses and computer literacy courses were introduced in the late seventies in grades 7-9 (junior high school) and in grades 10-11 for pupils who did not want to go deeper into IT concepts. Computer literacy dealt with some introduction 
to computer structure and programming but mainly with computer applications. The appreciation courses gave more emphasis on introducing programming concepts and algorithms.

Teaching computer literacy was widely accepted and widespread in the early eighties, but faded out later, as the use of computer applications became ubiquitous at younger ages.

Teaching of Computer Sciences at high school level [5] was introduced in the late seventies, similar to teaching of sciences. It has been accorded a status similar to sciences, as part of matriculation examinations and as criteria for admission to universities.

Two policy issues had to be considered:

- Should learning of Computer Sciences be restricted to an 'elite' of pupils, high achievers in maths and sciences, or should basic principles (at least) be open to almost any pupil capable of mastering some basic knowledge. The outcome was the development of basic modules providing insight into computer operation, programming and algorithmic approach. The basic modules became an introductory course to teaching of more advanced IT concepts and of scientific or professional applications. Other modules were developed at higher level for the more interested and gifted pupils. Those willing to dedicate more time were allowed to develop individual or group projects, as part of meeting their matriculation requirements.

- The language to be used for the programming parts of the curriculum. The choice was Pascal - the structured language considered best at those times; later on, use of Visual Basic and of Object Oriented languages was introduced.

Learning Computer Sciences is strongly related to having access to programming facilities. In the seventies, when relatively low cost microcomputers were not available, programming practice was provided by central laboratories, with multiterminal systems, card readers (cards marked with pencils) and printers. Pupils came in groups to run their programs or, much less convenient, pupils' delegates were bringing the marked cards of the class, running the batch and returning the prints to their class. These solutions, seeming ridiculous nowadays, provided the programming means to all schools that were not big enough and rich enough to provide in-school computing. Obviously, the use of central laboratories faded out at the end of seventies and beginning of eighties.

Education of IT professionals [12], as part of the technological education at high school level was introduced in the late sixties and became widespread in the seventies and eighties. It was extended to post-secondary education of one or two years, leading to education of IT technicians and practical engineers. Efforts have been made to keep the curricula updated by including new subjects of study - object oriented approach, artificial intelligence, computer communications and networks. 


\section{Information Technology within Learning Humanities, Sciences and Professions}

Integrating IT technology within the teaching of sciences and humanities started in the eighties and has been slowly accepted and widespread. It was related to use of word processors, spreadsheets, databases, specific computational and graphic applications, use of simulators for demonstration and laboratory experiments. The effort was considerable as the whole issue was new and unfamiliar to most staff involved. The use of IT tools was accepted and integrated into most subjects of study, for several as far as becoming part of the matriculation examination requirements.

On a parallel path of activity, integrating IT technology within the professional training of pupils getting their education in the technological tracks was attempted. It involved almost any profession - electronics, instrumentation, accounting, office automation, fashions, tourism, mechanics, drawing ... However, in this case the staff was more open minded - perhaps more aware that the profession is changing and the education must follow. It has been a main issue for several years, the first stage completed in the eighties. Ongoing updating will remain a necessity and never complete.

One of the difficulties related to this issue has been the complexity, size and price of real professional applications - not affordable or even justified for school uses. Using down-scaled simulators, cooperation with industry provide adequate solutions.

\section{Teachers Education, Training, Updating and Support}

In the early seventies, teachers had in fact no knowledge of IT or of its integration in the educational system, but the acting teachers were the ones that had to do the job. So, in-service training and updating of teachers has been a major and indispensable component of the integration of IT into any aspect of the educational activity at national scale.

On the other hand, education of new teachers, at Schools of Education and at Colleges of Education had to provide graduates competent to deal with aspects of IT in education.

\subsection{Teachers of Computer Sciences and Literacy}

Teaching of advanced subjects in Computer Sciences and Education of IT professionals requires teachers with adequate academic degrees and educational skills. The required number of that kind of teachers being rather limited, they were recruited among academic graduates.

Teaching of introductory Computer Sciences and Computer Literacy required a huge number of teachers. The only possible solution to this demand was to offer inservice training courses to any interested teacher. Many teachers of Mathematics, Science, Technologies and some teachers of Humanities volunteered to follow 
extensive training courses, about 400 hours of study, to get a license for teaching these subjects.

Teachers of technologies have been offered similar, but shorter, in-service training, covering a general introduction to computing and further specialization in the applications specific to the profession taught.

Following the basic training, updating with developments and discussing the implementation aspects and methodologies has been accomplished by teachers meetings - half day to two day seminars - and short courses, about 20 hours.

\subsection{Teachers Integrating Computers in Education}

The following is the opening paragraph of a paper published in 1987 [4]:

"With the current state of the art, and for the foreseeable future, the teacher is considered to be the principal element in any teaching/learning activity within the school system, at whatever technological level it may be

found. The teacher has to master the whole range of media put at his disposal, to coordinate their correct application and to adapt them to the specific needs of his class or individual students."

In-service teachers' training covered some basic concepts of computing, but the main topics covered methodologies of using the computers for learning and a sound knowledge of the systems used and of activities they provided. Resolving the difficulties that may occur while using computers, overcoming the fears and insecurities related to the operation of a rather sophisticated system, all these were an important aspect of the training effort.

Nevertheless, ongoing support and guidance in educational and technical matters had to be provided, in addition to the preliminary training. Involvement of teachers in the development of educational materials and in the interpretation of the records of students' activities and achievements proved to be a significant factor for acceptance by the teaching staff and for real improvement of the learning materials.

\subsection{Schools and Colleges of Education}

Most of the academic staff of the Schools of Education at Universities and of the Colleges of Education in the seventies had no knowledge of computers and their educational potential, some being rather skeptical about the 'new gadget'. This being the case, each year a new cohort of computer illiterate teachers joined the schools, adding to the burden of training and updating the school staff.

Two main actions aimed to change this situation [4]:

- Organizing courses, seminars to the academic staff, encouraging and providing support for research in the field improved the general approach to the subject and increased the number of interested staff members;

- A formal request by the Ministry of Education to include in the curricula computer related subjects resulted in adaptation of computer related subjects in the students' learning programs. 
An introductory course on 'Computer basics and their applications in Education' became compulsory to all students of education; additional elective courses were offered - e.g., specific to integration in specific subject matters, management of school computing centres.

The academic staff was encouraged to include use of computers in their own teaching to their students.

By the mid-eighties all Schools and Colleges of Education provided these curricula.

Studies leading to a combined degree in Computer Sciences and in Education were offered in several academic institutes, providing a source of licensed teachers needed by the high-schools.

\section{Computers in Educational Administration}

As already mentioned, some schools started the use of computers in educational administration on their own initiative. In the mid-eighties a systems analysis and feasibility study was initiated towards a national network of computerized educational administration providing services at school level and extending to local, regional and national levels.

This project, under the management of the Division of Data Systems of the Ministry, led to the specification of school management systems, with technical requirements as well as requirements for maintenance, training and support to school staff - teaching and administrative. Commercial firms were invited to develop and offer systems based on these specifications.

The objectives were defined as improvement of the administrative and pedagogical decision-making by: compiling and analysing data; locating and displaying exceptional cases; reducing administrative burden; tools for decision making [11]. The system consisted of a standard basic software kernel to which each school could add its supplemental components interfacing with the basic software. The basic modules were: student management; teacher management; subject management; achievements record and report; statistical analysis and report. Examples of add-on modules: curriculum and teaching aids management; library management; bookkeeping.

In this case, again, adequate training and support played an important role for successful assimilation and appreciable effort was invested in it: from convincing the school principals and the main managerial staff, up to ongoing and well organized counselling and guidance.

Later on, connecting the school systems to regional and national networks was considered.

\section{Years Later}

At the beginning of $21^{\text {th }}$ century wide scale networking with the WWW (World Wide Web), with all its related applications, was already a fact, and it has been expanding at a rate unknown before for any other technological means. 
Several plans regarding ICT in education were published in the late nineties and first decade of $21^{\text {st }}$ century.

Issues related to teaching of computer literacy, Computer Sciences, computer applications in science and technology and training of computer professionals were not mentioned anymore. This was because these matters had been already settled and accepted by the schooling system as regular subjects for teaching and examinations.

Issues related to ICT in education continue to be raised, as a main issue to be addressed. This may be explained by the fact that technology is changing, perhaps too fast for the educational system to keep track; but also it may be the outcome of a degree of dissatisfaction with the rate of integration ICT means in actual teaching: an inquiry carried out in 2010/11 revealed that many schools are lacking computers and part of the existing equipment is not advanced enough; a great part of teaching continues to be done without any involvement of ICT means. Some of the main difficulties pinpointed years ago have not been solved completely, and some reappeared, perhaps in the context of the new technologies.

A policy document published in the year 2000 [7] emphasizes the potential and expected outcomes of the information-rich new challenge. Many new issues had to be considered, while most of the existing issues and goals kept their relevance.

Some of the rather new goals mentioned:

- To provide the knowledge and proficiency needed to efficiently use the web in order to reach cultural, humanitarian and scientific sources; to provide an environment promoting self-search, collection and organization of knowledge to encourage self and autonomous learning;

- To support moral and ethical values in a society being deeply influenced by the technology;

- To give priority and to provide rich sources and encouragement for adaptation of the school staff to the new reality - remembering that youngsters are faster to grab the novelty;

- To support reliable connection of schools, kindergartens and homes to the educational network;

In January 2005, the government's Task Force for Advancement of Education in Israel published a general policy paper 'The National Policy on Education'- dealing with all aspects of the educational system, in general [13]. It was not dedicated to ICT in education but it contained several relevant recommendations. Among them some old but worth to mention, others rather new:

- In first and second grades the basic core-subjects shall be in mother tongue, mathematics and computer usage;

- The training of all educational and administrative staff shall cover integration of ICT in teaching;

- Curricula shall include integration of ICT in the contents, ways of teaching/learning and assessment. The options shall include use of computer based tools, information sources, learning materials, internet and communications;

- Education about ethical aspects of use and misuse of ICT shall be provided; 
- Assessment of schools shall include, among other factors, the use of ICT in learning and in the teaching means;

- ICT shall strengthen the contact among teachers, learners and community, the contact with pupils of other schools, with experts in different fields, remote learning and coaching;

A new plan of action for integration of ICT in education started in 2011 covering 200 'basic integrator schools' and 20 'advanced integrators'. The advanced ones are schools that have proven achievements in the field and are expected to demonstrate to the basic ones and lead their activity. All schools shall get digital projection facilities, wide band wired and wireless networks, a laptop for each teacher and on-line learning contents; the 'advanced' ones will have one laptop per 5 pupils, and intelligent digital blackboards.

Schools are expected to define institutional and individual plans for accomplishing ICT integration in pedagogical, administrative and social activities; to be active in development of learning materials; to set up a school website and use it for management of learning and of assignments, for reporting attendance and discipline problem.

Teachers are expected to start posting learning materials on the school's website; pupils shall start submitting home-work through the website; pupils shall collect information from the web and be able to prepare presentations using ICT means.

Despite the problems, the criticism, the impossibility of achieving all goals and expectations, despite the feeling that more and better could have been done, even if in many schools the teaching is still very similar to what has been, far reaching changes have already been achieved and many more are under way in the future. It may take, perhaps, 20 more years till the current days' of schooling will become history.

\section{References}

[1] A report of the activities of the committee on Computers in Education, a private document (1983) (in Hebrew)

[2] Barta, B.Z.: Computers in the Israeli Educational System. Computer in Education, North Holland (1981)

[3] Barta, B.Z.: Computers in the Israeli Educational System (1980-84). Computer in Education, North Holland (1985)

[4] Barta, B.Z.: Training of Educational Staff for the Information Technology Age, Prospects, vol. XVII(3). UNESCO (1987)

[5] Engel, E., Telem, M., Barta, B.Z.: Teaching of Informatics and Information Technology at High School Level - the Israeli Experience. In: Proceedings of the World Conference on Computers in Education. IFIP. Chapman \& Hall (1995)

[6] Maaseh Hoshev - Bulletin of the Information Processing Association of Israel (1976) (in Hebrew)

[7] Melamed, U.: Report of the Committee on ICT policy in the Education System. Israeli Ministry of Education (2000) (in Hebrew)

[8] Millin, D., Barta, B.Z.: Six Years of Computer Penetration into Primary Education: the Case of Israel. Education and Computing, 171-178 (1991) 
[9] Policy for Activities in the Field of Computers in Education. Ministry of Education and Culture (November 1986) (in Hebrew)

[10] Proposal for a National Program for Development of Computer Aided Teaching Systems, Ministry of Science and Development and Ministry of Communications (1985) (in Hebrew)

[11] Sagi, I., Gev, Y., Feinesser, A.: School Management Information System Authority in Israel, Information Technology in Educational Management, pp. 79-92. Chapman \& Hall (1995)

[12] Telem, M., Barta, B.Z.: New Trends within the Basic Training of IT Professionals in Israel. In: Proceedings of the IFIP W.G. 3.4 Working Conference. Elsevier Science Publishers (1992)

[13] The National Policy on Education, the government's Task Force for Advancement of Education in Israel (January 2005) (in Hebrew)

[14] 'Tomorrow 1998', Israeli Ministry of Education (August 1992) (in Hebrew) 